Supporting Information for

\title{
6-Arylmethylidene Penicillin-based Sulfone Inhibitors for Repurposing Antibiotic Efficiency in Priority Pathogens
}

Diana Rodríguez, ${ }^{\mathrm{a}}$ María Maneiro, ${ }^{\mathrm{a}}$ Juan C. Vázquez-Ucha, ${ }^{\mathrm{b}}$ Alejandro Beceiro, ${ }^{\mathrm{b}}$ and Concepción González-Bello ${ }^{\mathrm{a}, *}$

${ }^{a}$ Centro Singular de Investigación en Química Biolóxica e Materiais Moleculares (CiQUS), Departamento de Química Orgánica, Universidade de Santiago de Compostela, Jenaro de la Fuente s/n, 15782 Santiago de Compostela, Spain.E-mail: concepcion.gonzalez.bello@usc.es

${ }^{b}$ Servicio de Microbiología do Complexo Hospitalario Universitario da Coruña (CHUAC), Instituto de Investigación Biomédica da Coruña (INIBIC), Xubias de Arriba, 84, 15006 A Coruña, Spain.

Table of Contents

1. Figure $\mathrm{S} 1$

2. Figure $\mathrm{S} 2$

S3

3. Figure $\mathrm{S} 3$

S4

4. Figure $\mathrm{S} 4$

S5

5. Figure S5

S5

6. NMR spectra

S6 

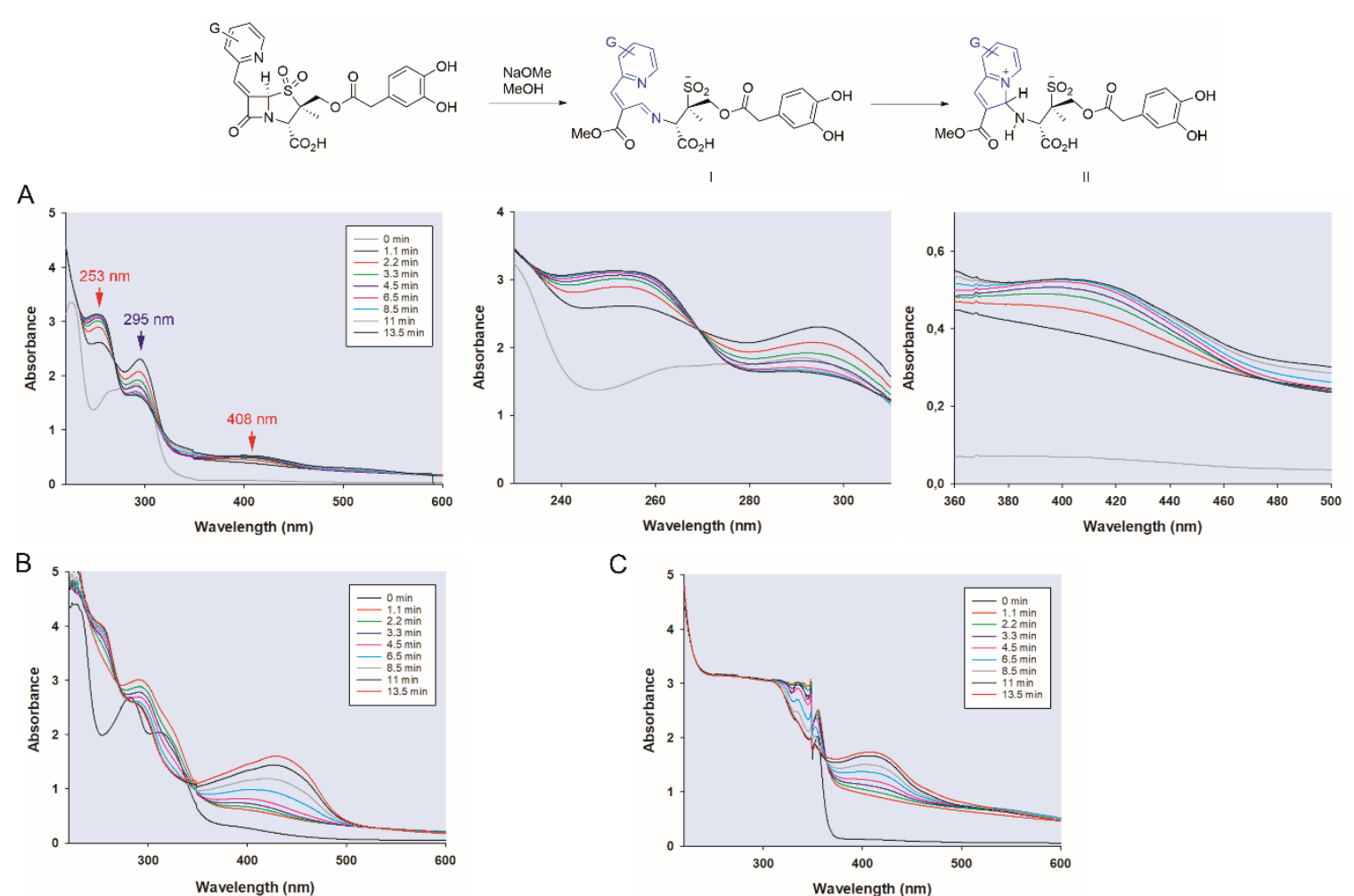

D
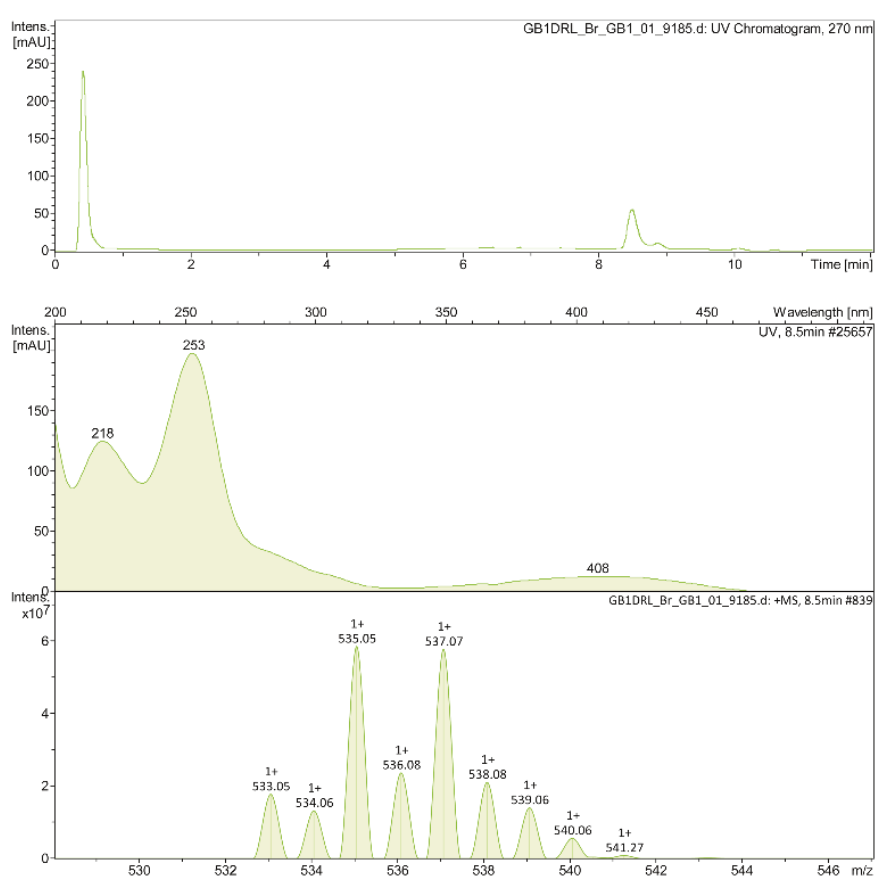

Figure S1. Monitoring the formation of the indolizine derivatives of ligands $\mathbf{3}, \mathbf{5}$ and $\mathbf{7}$ by UV-Vis spectroscopy after treatment with 1 equivalent of $\mathrm{NaOMe}\left(1 \mathrm{M}\right.$ in $\mathrm{MeOH}$ ) at $25^{\circ} \mathrm{C}$ for $15 \mathrm{~min}$ : (A) compound 3; (B) compound 5; (C) compound 7. Note that during the course of the reaction, the formation of a band centered at $295 \mathrm{~nm}$ (for ligand $\mathbf{3}$ ) was initially observed. This band progressively decreased as two new bands centered at $253 \mathrm{~nm}$ and $408 \mathrm{~nm}$ appeared. These bands would be due to the initial formation of conjugated imine I that subsequently undergoes a intramolecular cyclization reaction to give II. (D) HPLC chromatogram of the reaction mixture of compound $\mathbf{3}$ and mass spectra of its main peak, which would correspond to intermediate II with loss of $\mathrm{SO}_{2}$. 

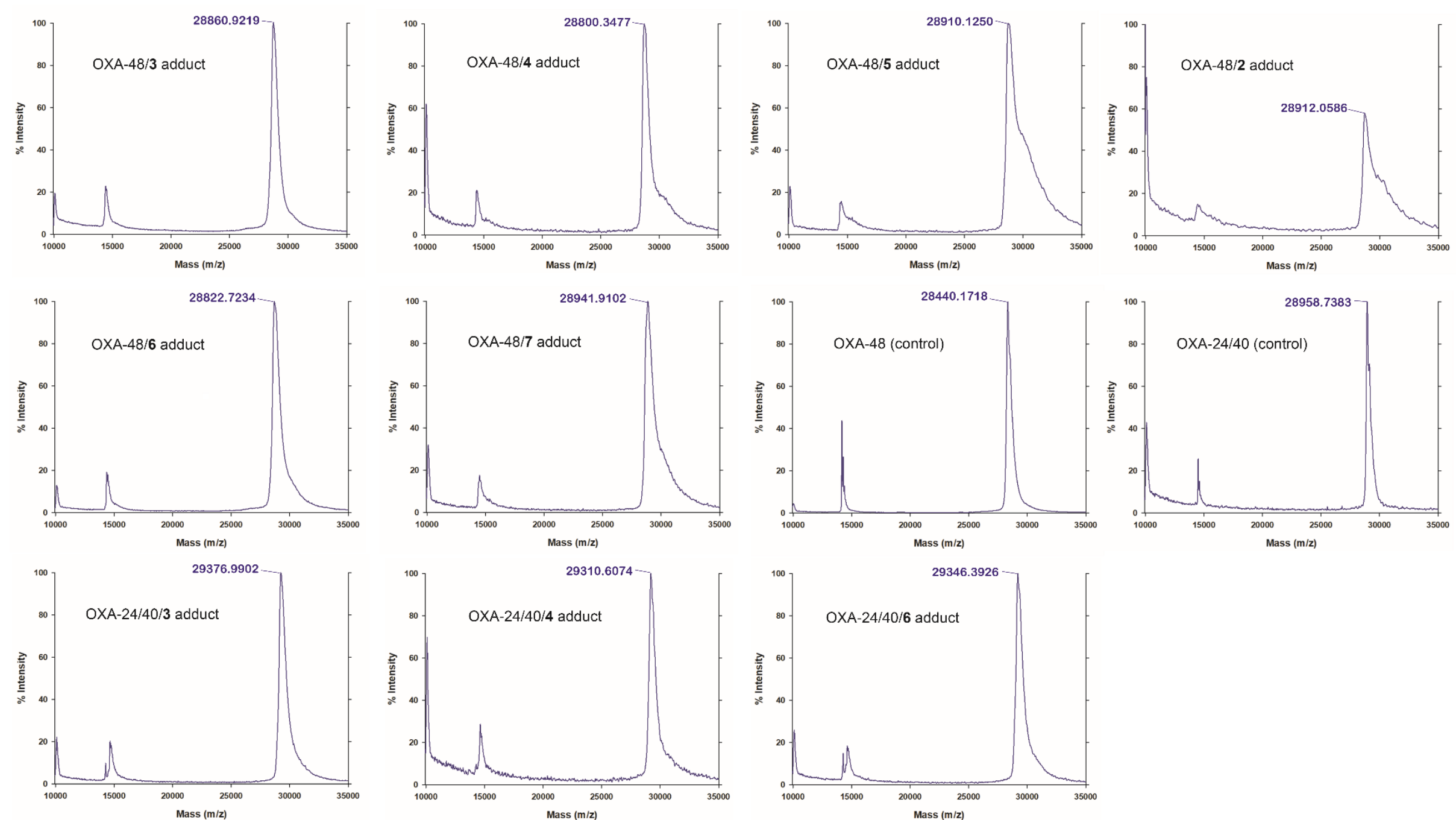

Figure S2. MALDI spectra examples of samples of OXA-48 and OXA-24/40 after incubation with ligands 2-7. The spectra of the wild-type enzymes are also shown as a control. Incubation conditions were Tris. $\mathrm{HCl}(50 \mathrm{mM}, \mathrm{pH} 7.0), 150 \mathrm{mM} \mathrm{NaCl}, 1 \mathrm{mM} \mathrm{EDTA}, 25{ }^{\circ} \mathrm{C}$ and $(1: 100)$ protein/ligand ratio, $30 \mathrm{~min}$. After incubation and for MALDI analysis, the samples were successively washed with $5 \mathrm{mM}$ sodium bicarbonate by centrifugation at $4{ }^{\circ} \mathrm{C}$ using Amicon ${ }^{\circledR}$ centrifugal filters and concentrated. Sinapic acid was used as a matrix. 
A

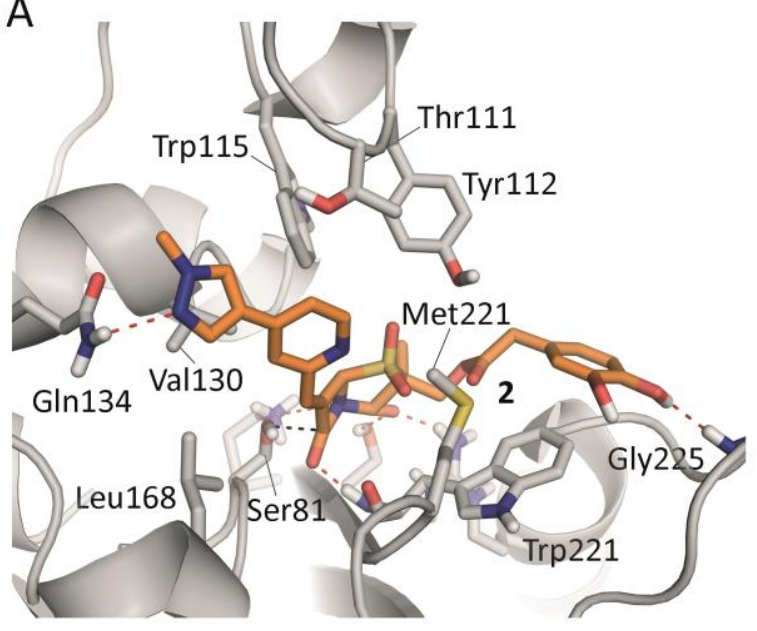

C

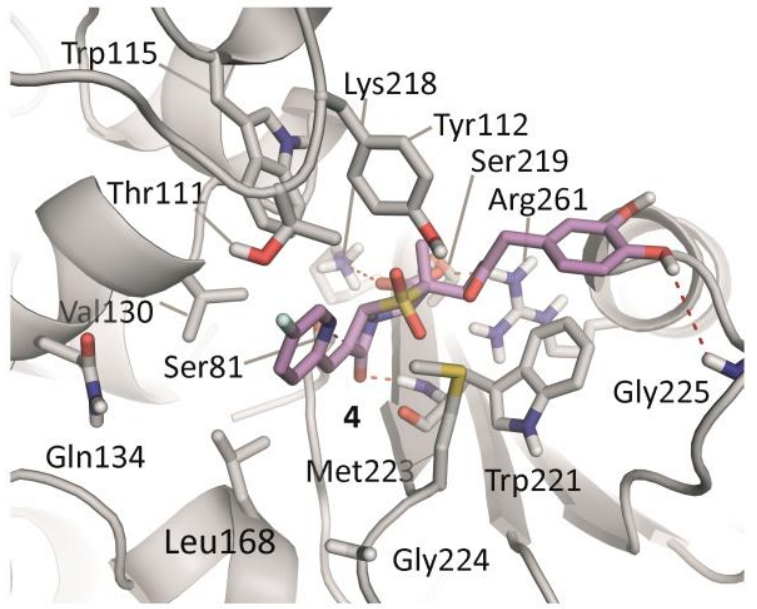

$\mathrm{E}$

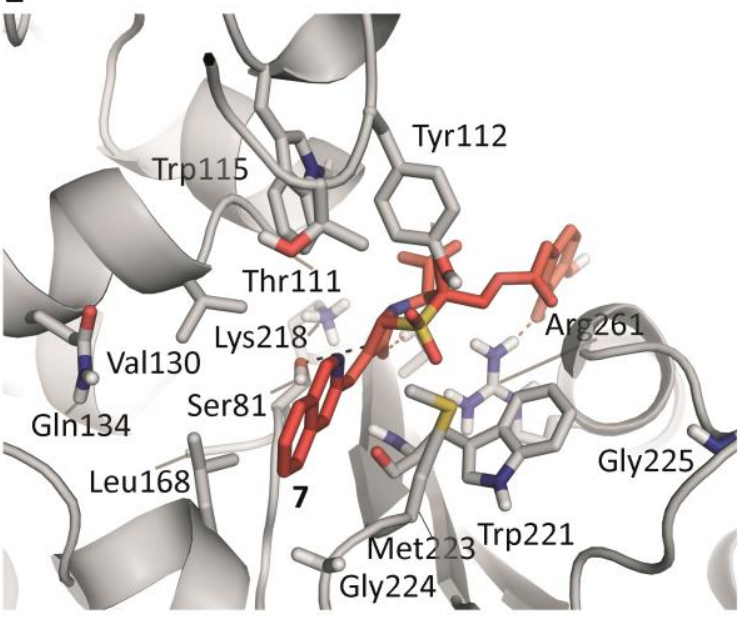

B

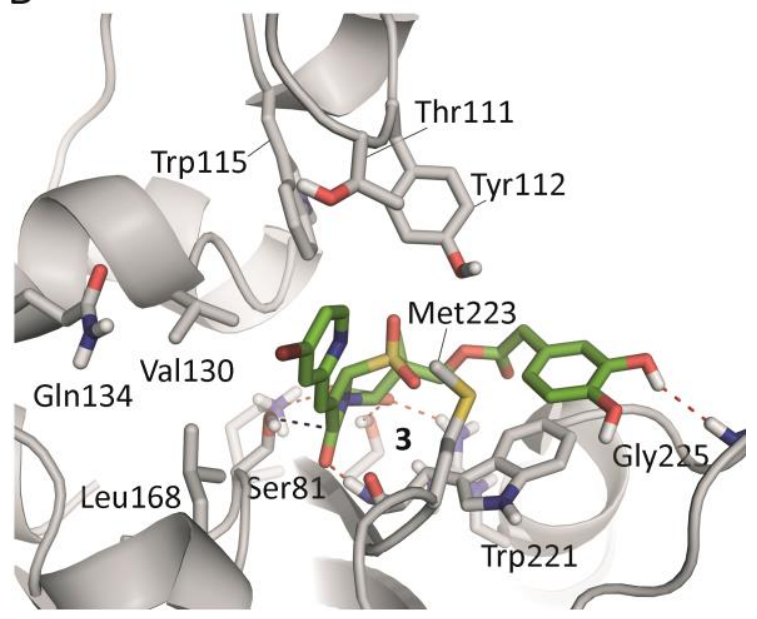

D

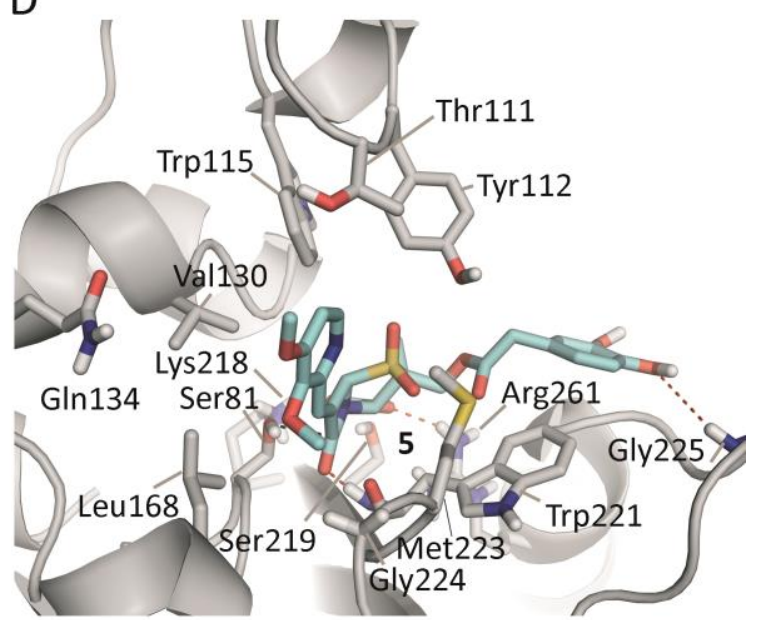

$\mathrm{F}$

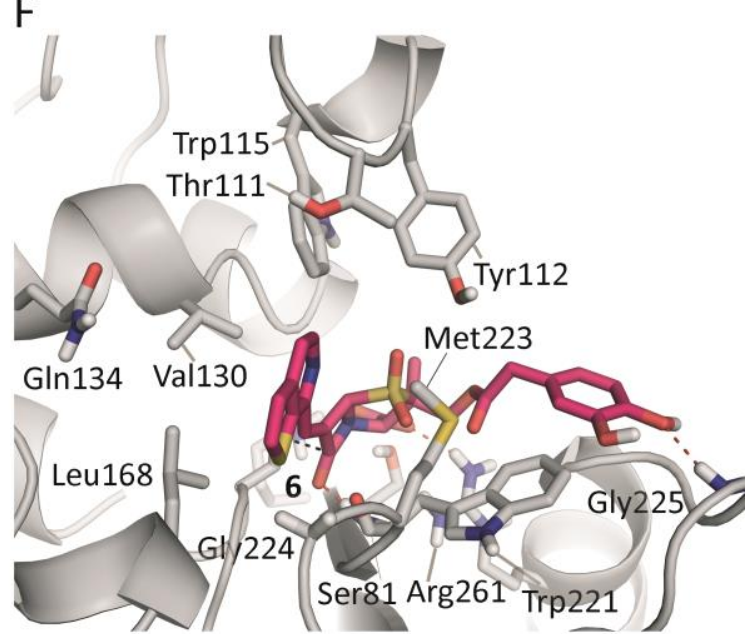

Figure S3. Detailed view of the binding interactions of inhibitors 2 (A), 3 (B), 4 (C), 5 (D), 7 (E) and 6 (F) in the active site of the OXA-24/40 from A. baumannii enzyme. Relevant side chain residues are shown and labeled. Polar (red) interactions between ligands and enzyme residues are shown. Relative distances between the hydroxyl group of catalytic serine and the carbonyl group of the $\beta$ lactam ring (2.8-3.4 $\AA$ ) are shown as black dashed lines. 


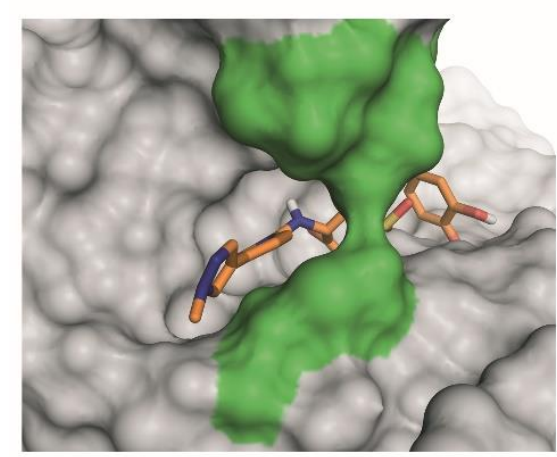

OXA-24/40/2 adduct

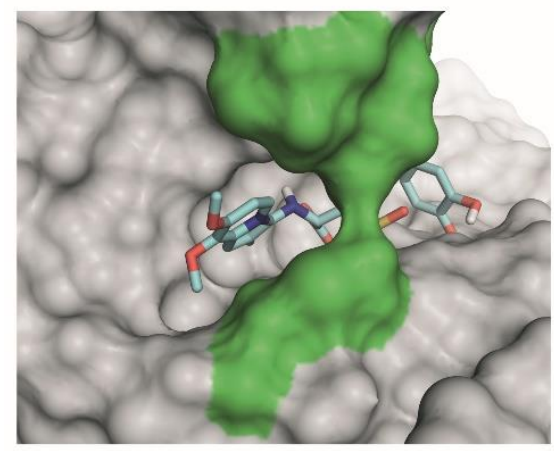

OXA-24/40/5 adduct

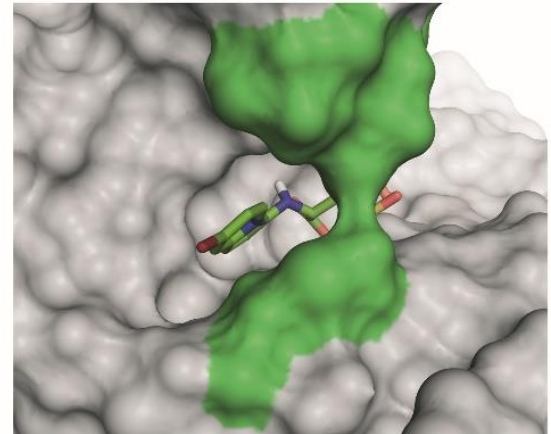

OXA-24/40/3 adduct

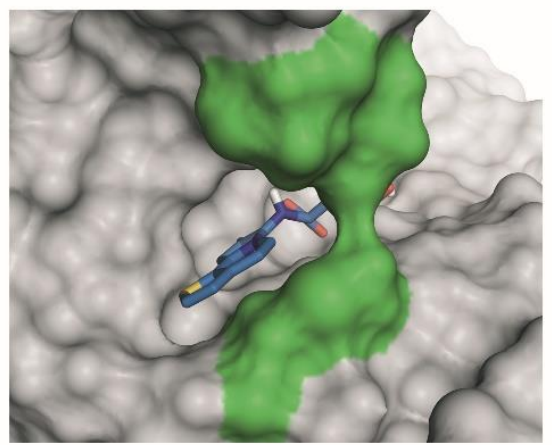

OXA-24/40/6 adduct

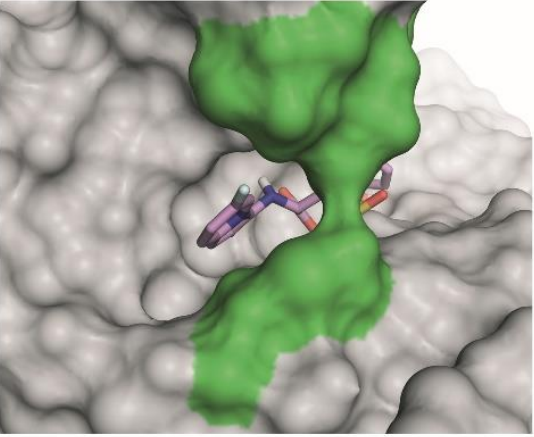

OXA-24/40/4 adduct

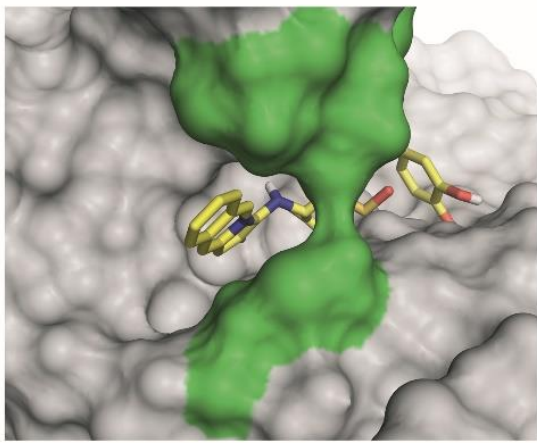

OXA-24/40/7 adduct

Figure S4. Selected views of the inactivation of OXA-24/40 from A. baumannii by ligands 2-7 obtained by covalent molecular docking studies. The tunnel-like entrance of the active site involving residues Tyr112 and Met223 is highlighted in green.

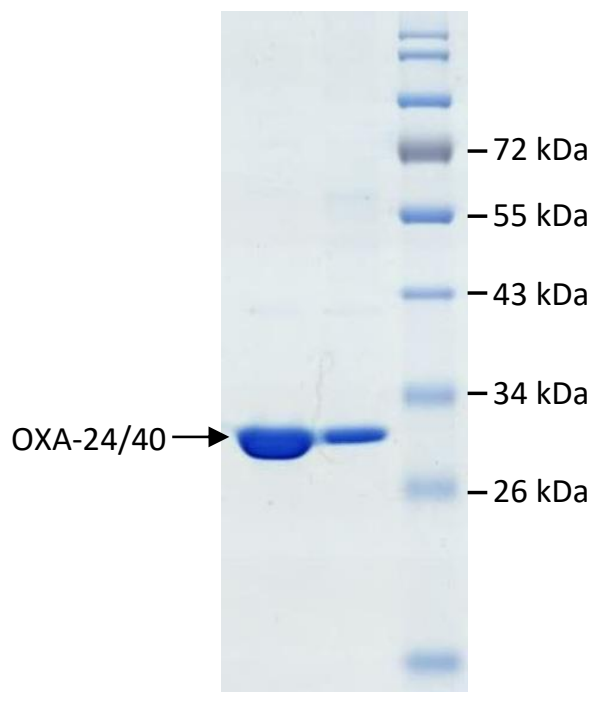

Figure S5. SDS-PAGE analysis of purified OXA-24/40 $\beta$-lactamase enzyme. 

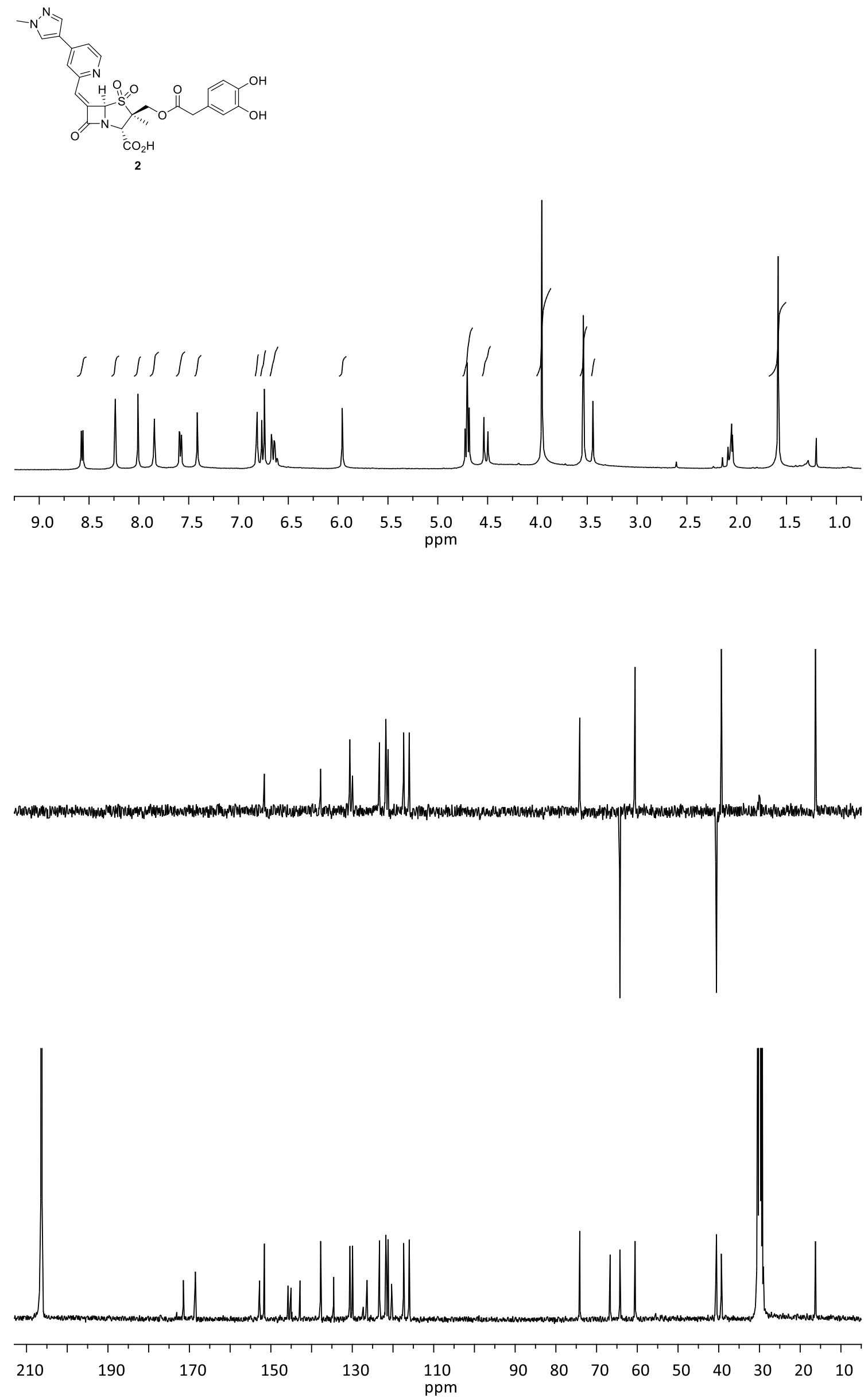

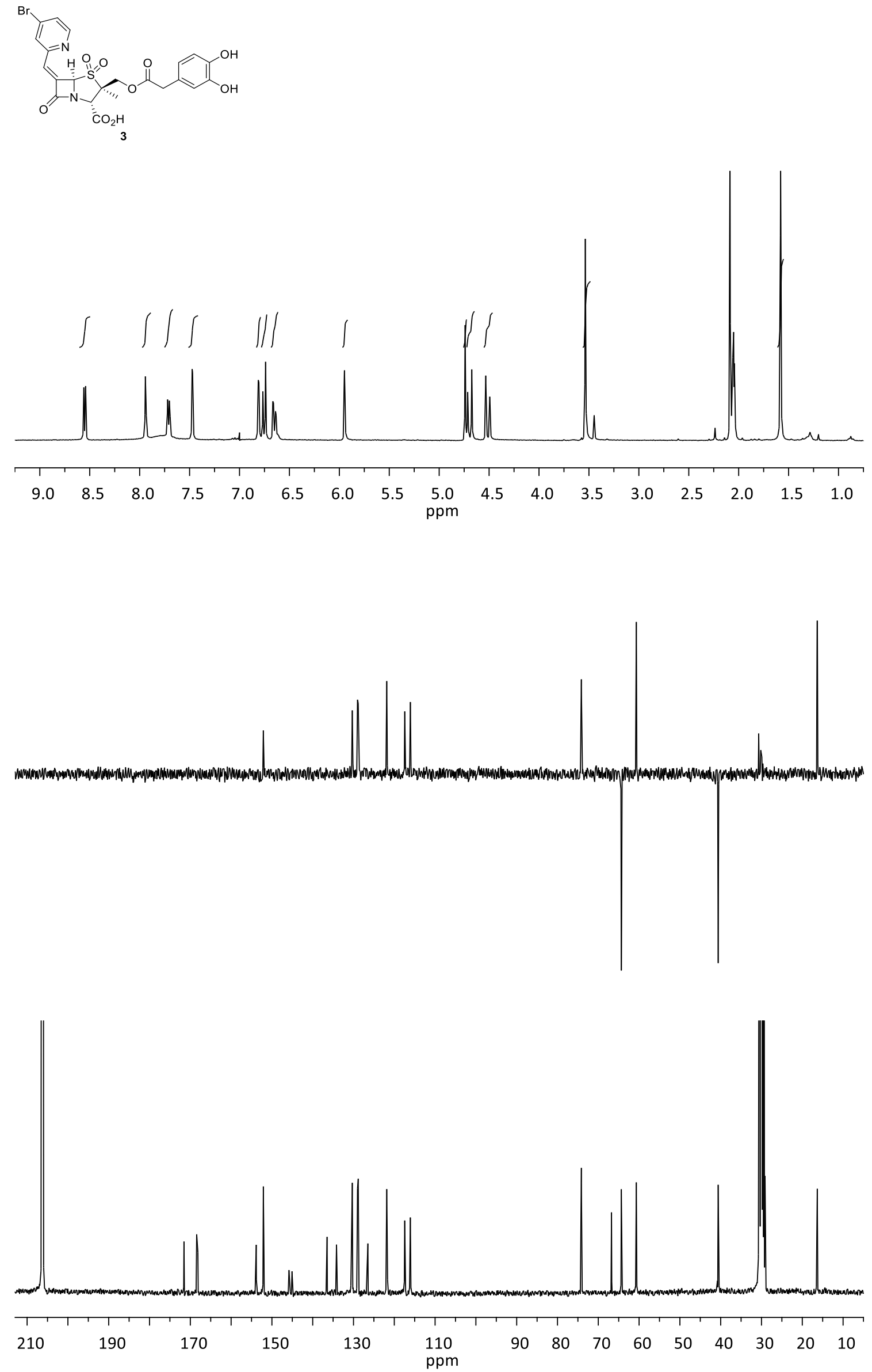

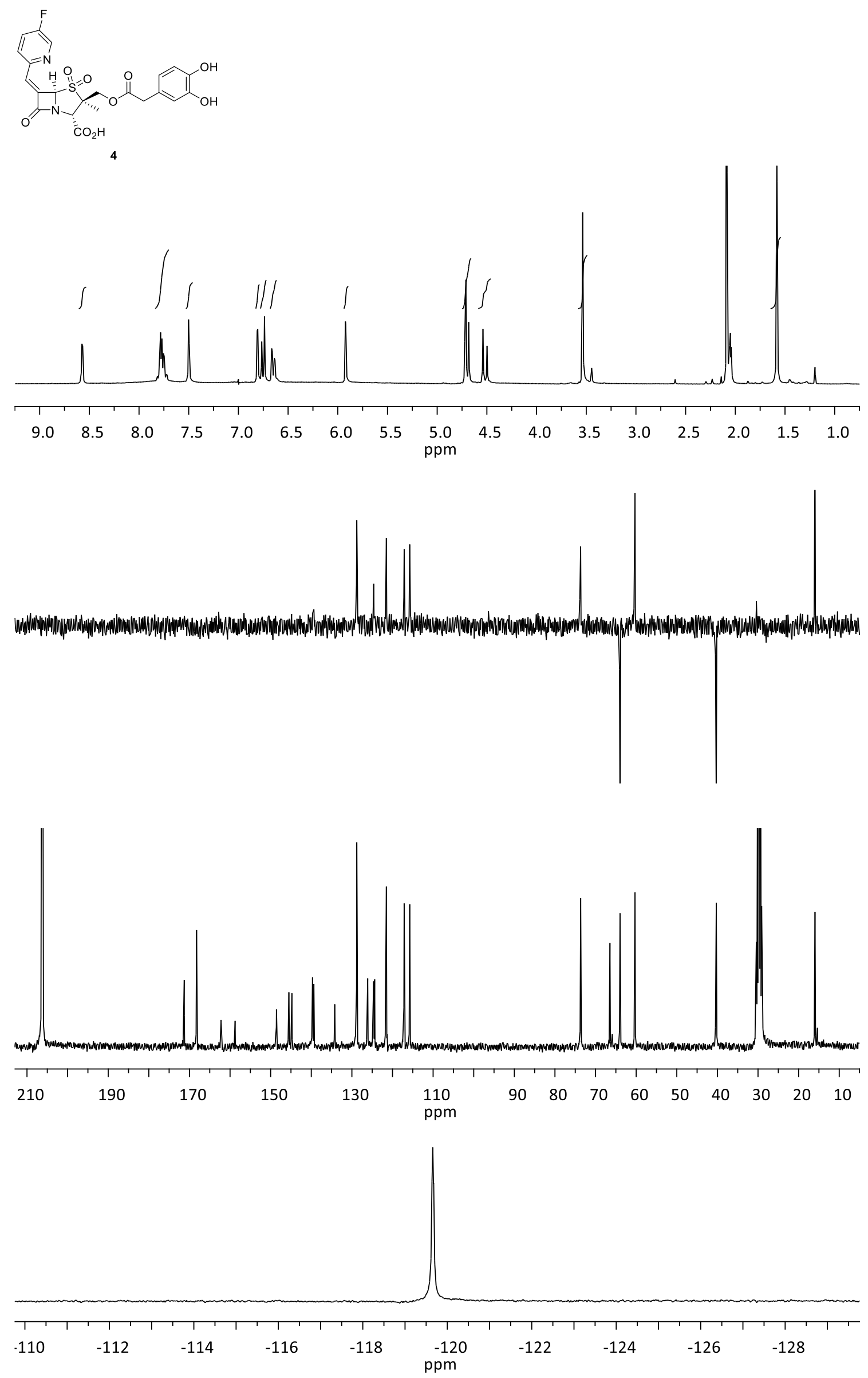

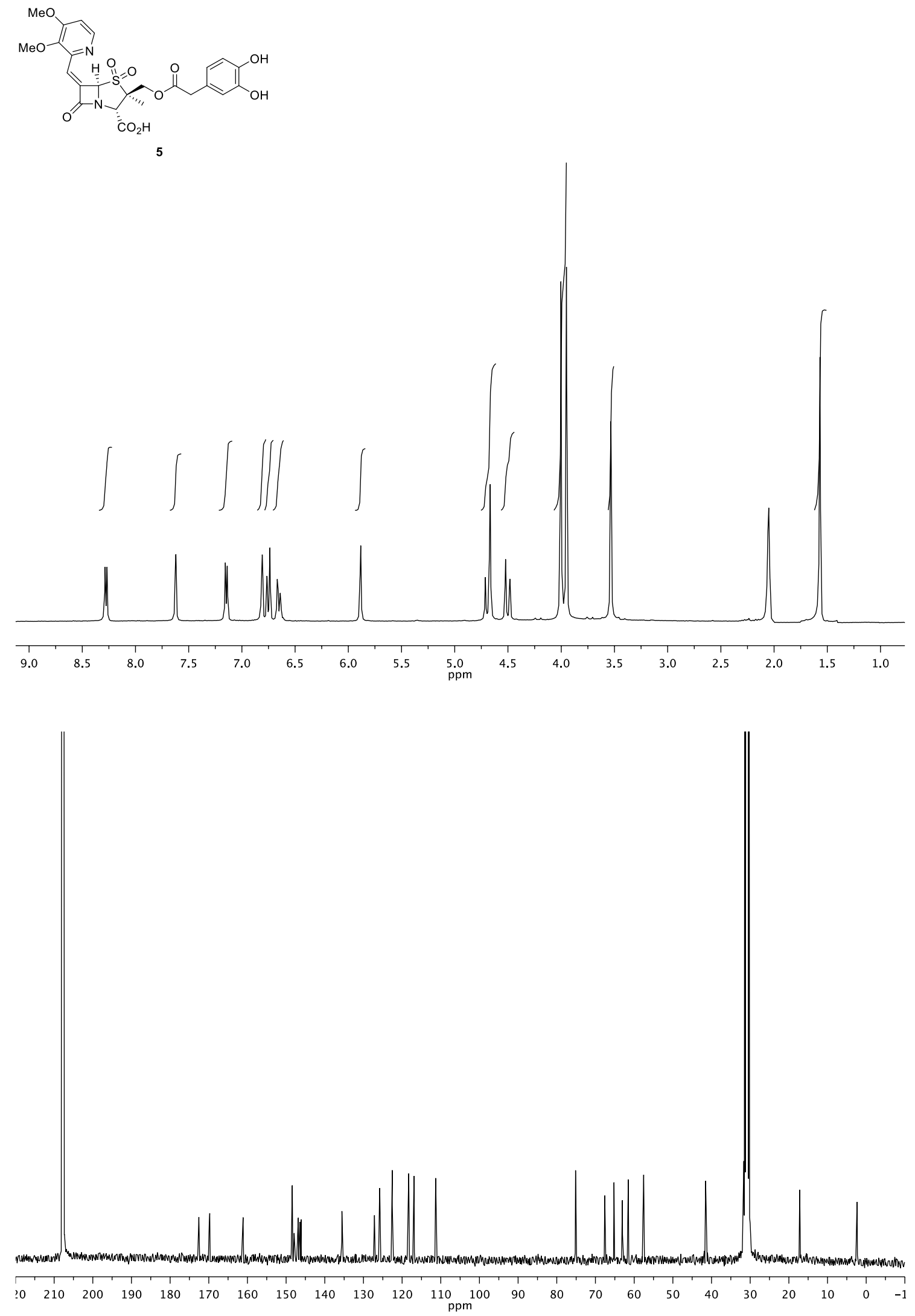

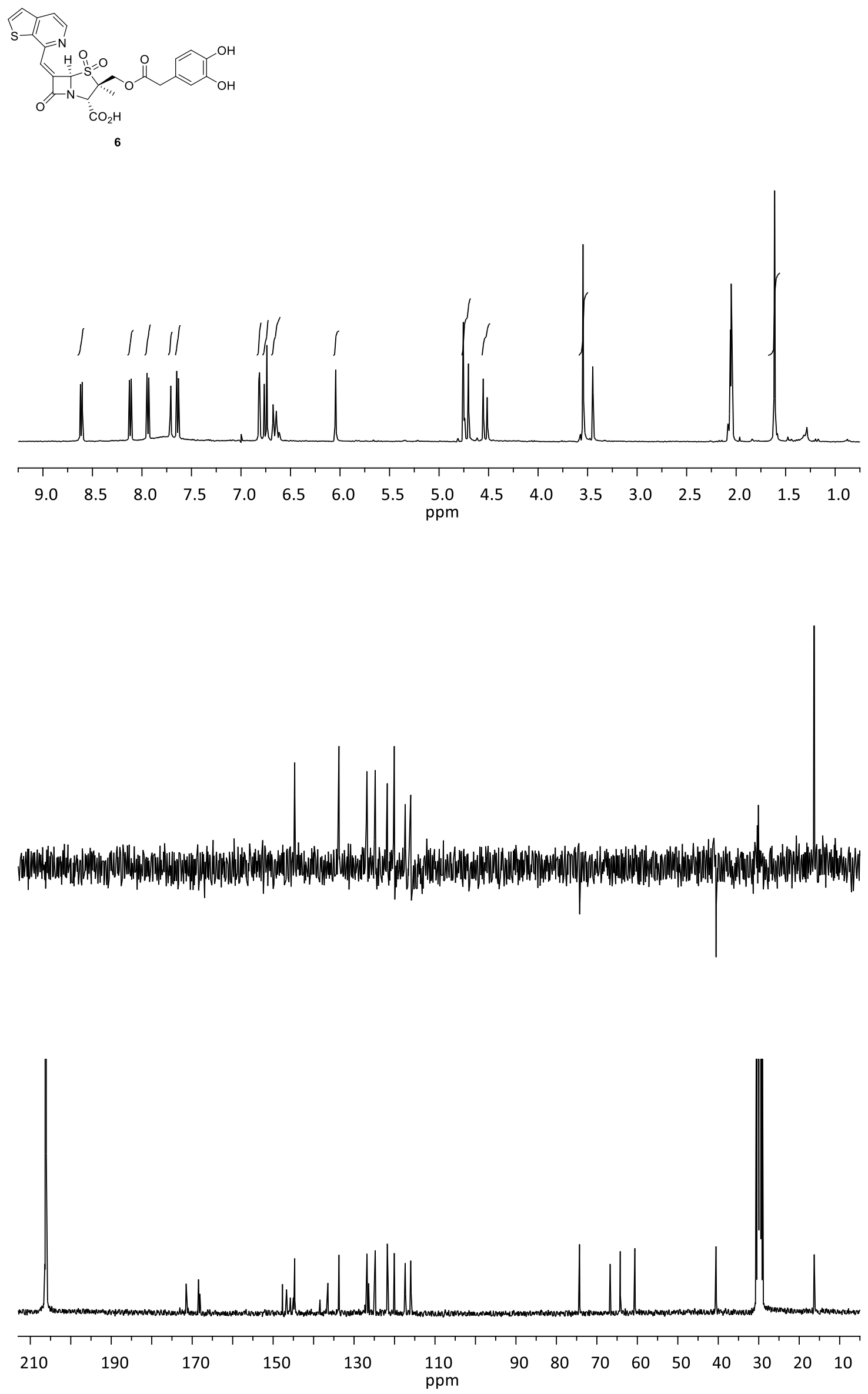

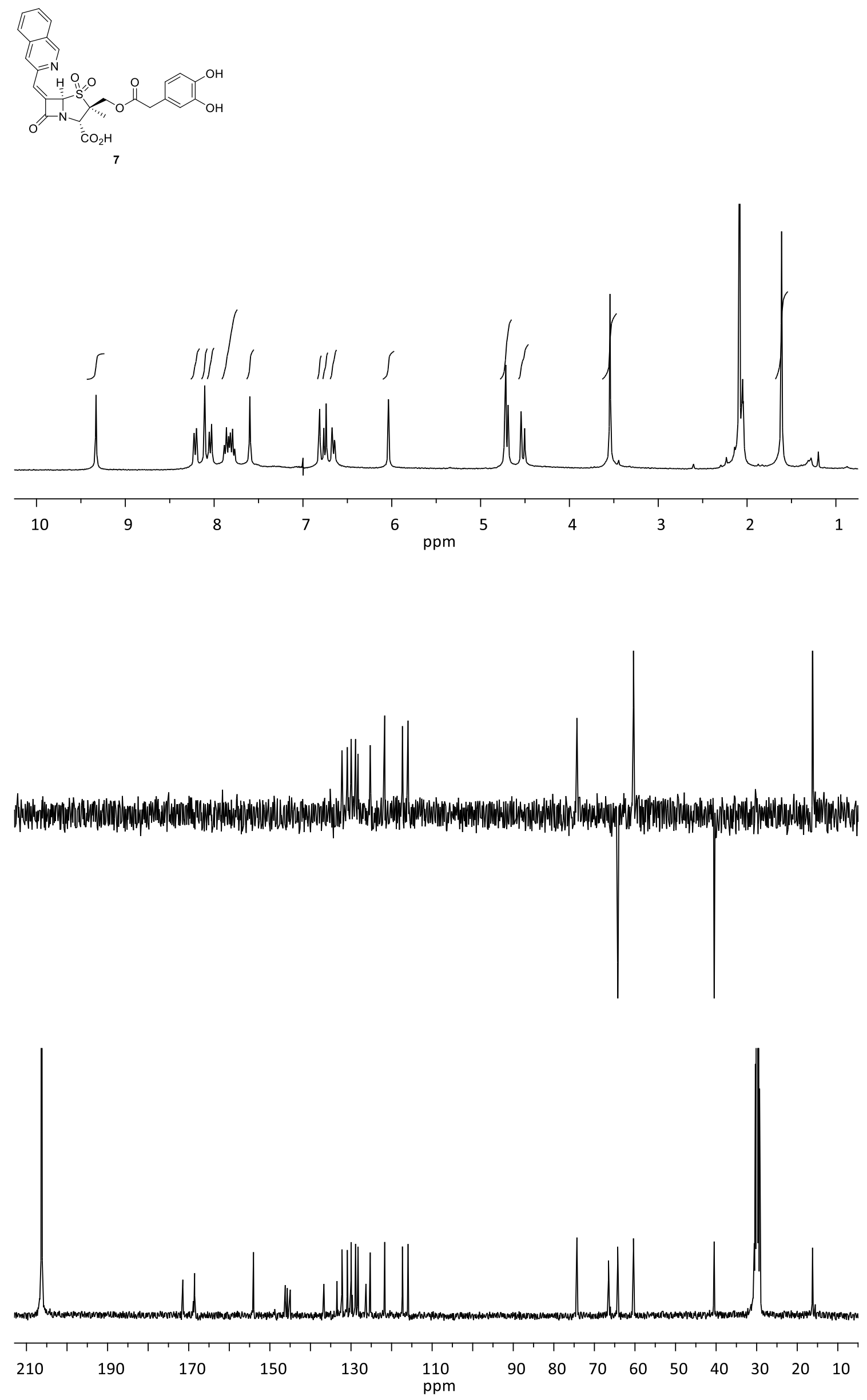